\title{
The simulations of helical blade interaction with ice
}

\author{
Ekaterina Abramova ${ }^{1}$, Georgy Mashorin, Yuri Molev ${ }^{1, *}$, and Aleksandr Sogin ${ }^{1}$ \\ ${ }^{1}$ Nizhny Novgorod State Technical University, 603950 N.Novgorod, Minin st., 24, Russia
}

\begin{abstract}
This paper presents the methodology for determination of the parameters of interaction between a rotary-screw vehicle and ice surface. The key parameter is the value of ice cutting force by means of a screw blade. The methodology allowed to obtain results, showing that the value of the cutting force depends on shape of the helical blade. Developed model of the cutting force allowed to conclude that that the width of the cut exerts the greatest influence on the cutting force, but depth and speed of the cutting have the less influence. Analysis of the study results provides the opportunity to find rational geometric parameters of the helical blade. The methodology can be applied for rotary-screw all-terrain vehicles designing.
\end{abstract}

\section{Introduction}

The requirements of quantity and quality of all-terrain vehicles can't be overestimated, considering the volume of Russian Federation demand. Russia is on 181st place of 195 countries rated according to the population density (the population density in Komi Republic, in the Arkhangelsk region, Yakutia, the Magadan region, Chukchi Peninsular is smaller than that of Mongolia, who takes the last place in the list). To provide proportional development of mentioned areas it's necessary to solve the problem of road infrastructure in the remote northern zones of Russia. The solution can be achieved by two ways: by building and servicing new motorways or by making universal all-terrain vehicles. However, the small population density, small passenger and cargo traffic, the high cost of road servicing, especially in winter, suggests wider application of all-terrain vehicles.

Current transport system considers water transportations from the south to the north during summer. After that, goods are transported from the terminal port to their destination by ground transport. In winter, the task of transportation is solved by all-terrain vehicles. But limited amphibious capacity of wheel and caterpillar vehicles, though, as well as the lack of adequate safety conditions necessitate the use of vehicles which could move well on snow, ice, water, and could pass from one environment to another, including passing from open water to ice.

Nowadays, only rotary-screw vehicles are able to solve the mentioned above task $[1,2,3,4,5,6,7]$. However, such vehicles haven't been produced serially. It makes many additional issues in manufacturing of such vehicles. The key issues are: the estimation of

${ }^{*}$ Corresponding author: moleff@yandex.ru 
traction balance; the estimation of resistance in different environments. Therefore, the aim is of vital importance.

Ice is the environment where rotary-screw vehicles fully use their advantages in comparison with other all-terrain vehicles. These vehicles have almost "absolute" ability to move in such conditions (if there are no obvious design mistakes in engineering or human factor errors in operation and service) and have extremely high towing force. As well, motion on ice surface reduces disadvantages of rotary-screw vehicles, i.e. high vibration and environment destruction $[8,9,10]$. Ice surface increase stability and operability of the vehicle $[11,12,13]$. Rotary-screw vehicles can travel on any ice, however thick and solid it is.

\section{Methods}

The theory of earthwork notes that cutting force does not only depend on the area, angle and the speed of cutting, but on the cut lateral surfaces degree of freedom.

In general, the total value of the ice cutting resistance force for the helical blade depends on two components. The first is the resistance force of ice to the front part of the helical blade. This component is determined by the width and form of the blade cutting area in the examined conditions and the cutting speed. The second is the resistance force of ice to the lateral shear destruction line, which does not contact directly with the cutting element of the helical blade, but is broken due to the tension arising in ice during cutting. The first component can be easily estimated thanks to the works dedicated to ice destruction $[14,15,16]$ where it complies with the requirement of cutting without side walls.

To estimate the second component we should turn to the continuum theory $[17,18,19]$. According to the equations deduced within this study, based on the so-called Flaman task generalized for the strip load case, the solution of the problem looks:

$$
\begin{gathered}
\sigma_{x}=\frac{3 P_{p e 3}}{2 \pi}\left(\frac{x^{2} z}{R^{5}}+\frac{1-2 v}{3}\left(\frac{1}{R(R+z)}-\frac{(2 R+z) x^{2}}{R^{3}(R+z)^{2}}-\frac{z}{R^{3}}\right)\right) \\
\sigma_{y}=\frac{3 P_{p e 3}}{2 \pi}\left(\frac{y^{2} z}{R^{5}}+\frac{1-2 v}{3}\left(\frac{1}{R(R+z)}-\frac{(2 R+z) y^{2}}{R^{3}(R+z)^{2}}-\frac{z}{R^{3}}\right)\right) \\
\tau_{x y}=\frac{3 P_{p e 3}}{2 \pi}\left(\frac{x y z}{R^{5}}-\frac{1-2 v}{3} \frac{(2 R+z) x y}{R^{3}(R+z)^{2}}\right)
\end{gathered}
$$

Where: $\mathrm{x}, \mathrm{y}$ and $\mathrm{z}$ are the coordinates of the studied point, and $\mathrm{R}$ is the radius, equaling how: $\sqrt{x^{2}+y^{2}+z^{2}}$.

Considering the fact that the destruction of lateral faces occurs exactly on the partition of the ice base, quantity $z$ is equaled to 0 . Then in the course of some conversions, the equation of the ice lateral destruction surface looks:

$$
\frac{x y}{\left(x^{2}+y^{2}\right)^{2}}-\frac{\operatorname{tg} \alpha}{2\left(x^{2}+y^{2}\right)} \sqrt{\left(1-\frac{2 x^{2}}{\left(x^{2}+y^{2}\right)}\right)^{2}+\left(1-\frac{2 y^{2}}{\left(x^{2}+y^{2}\right)}\right)^{2}}=\frac{C_{0} \pi}{P_{P}(1-2 v)}
$$

This equation has no strict mathematical solution. However, the values for the distinguished points can be obtained. This way, if the condition that $x=0$ is met, that is for the cutting plane, this equation will look like this:

$$
y=1 / 2 \sqrt{\frac{P_{P}(1-2 v) \operatorname{tg} \alpha}{C_{0} \pi}}
$$


Because ice properties in such a small amount are completely isotropic, then on the line perpendicular to the plane of cutting, described by the relation $y=0$, the coordinate of the rupture curve will be found according the similar formula:

$$
x=1 / 2 \sqrt{\frac{P_{P}(1-2 v) \operatorname{tg} \alpha}{C_{0} \pi}}
$$

Analyzing expressions 5 and 6 we can come to the conclusion that the graphic form of the obtained curve will be symmetrical relative to the axis described by the mathematic expression $x=y$. The coordinate of the studied curve estimates the maximum withdrawal of the rupture curve from the borderline between the cutting edge and the ice:

$$
x=y=1 / 4 \sqrt{\frac{P_{P}(1-2 v)}{C_{0} \pi}}
$$

When solving this expression by way of the graphic method using mathematical application Mathcad it was found that the maximal spreading of the side shear line in its height conforms to the condition:

$$
\left.y_{\text {max }}=1,2 x=1 / 4 \sqrt{\frac{P_{P}(1-2 v)}{C_{0} \pi}(2,4-0,2 \sqrt{2} \operatorname{tg} \alpha}\right)
$$

In case the cutting depth exceeds this value, then the ice will crumble inside the cut face. In this case, the cutting scheme will have the name - "angular in the slot", and the value of the cutting blocking coefficient will be equal to 1.5 .

Thus, the total force of ice cutting by the helical blade element can be found from the following expression [19]:

$$
\left.P=\frac{P_{0}}{1+k t_{0}} * h^{n}[1+\beta(b-1)](1+k t)(1+\xi V)\left[1+\varsigma\left(\alpha-40^{o}\right)^{2}\right] \mu\right)
$$

Where: $\boldsymbol{P}_{\boldsymbol{0}}$ - the calibration cutting force derived from cutting ice $0.01 \mathrm{~m}$ thick at the ice temperature $0^{\circ} \mathrm{C}$, cutting angle being 90 degrees and the cutting rate being $0 \mathrm{mps} ; \boldsymbol{k}-$ the coefficient of ice strength properties change, depending on the temperature which equals 0.04 $\mathrm{H} /$ degrees; $\boldsymbol{\xi}$ - the coefficient of ice strength properties change, depending on load application rate equaling $9.87 \mathrm{H} / \mathrm{cm} ; \boldsymbol{n}$ - the coefficient of the cutting force, depending on the depth of cutting that equals $0.47 ; \boldsymbol{\beta}$ - the coefficient of cutting force change, depending on the cutter's width equaling $0.865 ; \zeta$ - the coefficient of cutting force change, depending on the angle of cutting equaling to $3,2 * 10^{-3}$ (1/degrees); $\boldsymbol{\mu}$ - the cutting blockage coefficient assumed as equal to 1.5 for the cutting condition in the mode "angular opening"; $\boldsymbol{b}$ - the width of the screw blade; $\boldsymbol{V}$ - the rate of cutting, determined by the distance between the cutting point and the rotor rotation axis and the rotor's rotation rate: $V=\left(h_{1}+D / 2\right) \omega$, $\mathrm{V}=\left(\mathrm{h}_{1}+\mathrm{D} / 2\right) \omega$, where $\boldsymbol{D}$ - the base cylinder diameter and $\boldsymbol{\omega}$ is the rotor's angular velocity.

The effect of the helical blade shape can be found by inserting the value of $h_{1}, V_{P}$ into expression 10 as mathematical dependences on $b$, which will look like the following for the triangular cross-section of the blade:

$$
h=A b ; \quad V=A b \omega+\frac{D \omega}{2}
$$

Where: $\boldsymbol{A}$ - the tangent of the slope angle of the helical blade side to the base cylinder surface.

Next, indicating the expression $P=P_{0}\left[1+\varsigma\left(\alpha-40^{o}\right)^{2}\right\rfloor \mu$, in equation 9 as $\mathrm{P}$, we will have the value of ice cutting force of the helical blade in the conditions of constant temperature, looking like [20]: 


$$
\begin{aligned}
& P=\int_{0}^{\mathrm{B}}\left(A^{\mathrm{n}} P_{1} * b^{n-1}(1-\beta)+A^{\mathrm{n}} \beta P_{1}^{*} b^{n}+\xi A^{\mathrm{n}+1} \omega P_{1} * b^{n}(1-\beta)+,\right. \\
& \left.+\xi A^{\mathrm{n}+1} \omega \beta P_{1} * b^{n+1}+\xi A^{\mathrm{n}+1} 0,5 D \omega P_{1} * b^{n-1}(1-\beta)+0,5 D A^{\mathrm{n}} \beta P_{1} * b^{n}\right) \mathrm{db}, \\
& \text { or: } \\
& P=\int_{0}^{\mathrm{B}}\left(A^{\mathrm{n}} P_{1}(1-\beta)+\xi A^{\mathrm{n}+1} 0,5 D \omega P_{1}(1-\beta) b^{n-1} d b+\int_{0}^{B} \xi A^{\mathrm{n}+1} \omega \beta P_{1} * b^{n+1} d b+,\right. \\
& \left.\quad+\int_{0}^{B}\left(A^{\mathrm{n}} \beta P_{1}+\xi A^{\mathrm{n}+1} \omega P_{1} *(1-\beta)+0,5 D A^{\mathrm{n}} \beta P_{1}\right) b^{n}\right) \mathrm{db},
\end{aligned}
$$

By solving the obtained integral equations we will have:

$$
\begin{gathered}
P=\left(\frac{A^{\mathrm{n}} P_{1}(1-\beta)+\xi A^{\mathrm{n}+1} 0,5 D \omega P_{1}(1-\beta)}{\mathrm{n}-1} b^{n}+\frac{\xi A^{\mathrm{n}+1} \omega \beta P_{1} \cdot b^{n+2}}{n+1}+,\right. \\
+\left(\frac{A^{\mathrm{n}} \beta P_{1}+\xi A^{\mathrm{n}+1} \omega P_{1} *(1-\beta)+0,5 D A^{\mathrm{n}} \beta P_{1}}{n} b^{n+1},\right.
\end{gathered}
$$

Dividing the derived equation by the value of the initial cutting force $\boldsymbol{P}_{1}$ we will get the relative change of the penetration force of the screw blade into ice, depending on the parameters of the rotary-screw mover:

$$
\begin{aligned}
\Psi=\frac{P}{P_{1}}= & \frac{A^{\mathrm{n}}(1-\beta)+\xi A^{\mathrm{n}+1} 0,5 D \omega(1-\beta)}{\mathrm{n}-1} b^{n}+\frac{\xi A^{\mathrm{n}+1} \omega \beta \cdot b^{n+2}}{n+1}+, \\
& +\left(\frac{A^{\mathrm{n}} \beta+\xi A^{\mathrm{n}+1} \omega^{*}(1-\beta)+0,5 D A^{\mathrm{n}} \beta}{n} b^{n+1},\right.
\end{aligned}
$$

\section{Results}

The obtained dependence, the solutions of which are shown in Fig. 1, makes it possible to estimate the effect of any parameter of the rotor on the energy intensity of the helical blade penetration into ice. The solutions, shown in the graph, enable us to conclude that not only width and edge angle of the blade (determined by parameter A) effect on the cutting force, but the diameter of the base cylinder affects as well, determining the rate of cutting.

The obtained results were applied in designing of the prototype of the rotary-screw allterrain vehicle (Fig.2). The work was performed with financial support of the Ministry of Science and Education within "Research and development in the priority sectors of Russia's science and technology complex of 2014-2020” №14.577.21.0222. The topic of the project is "The design of the test model of the independent amphibious transport technological complex with intellectual control and navigation system for all-year borehole exploring on the Arctic shelf'. 


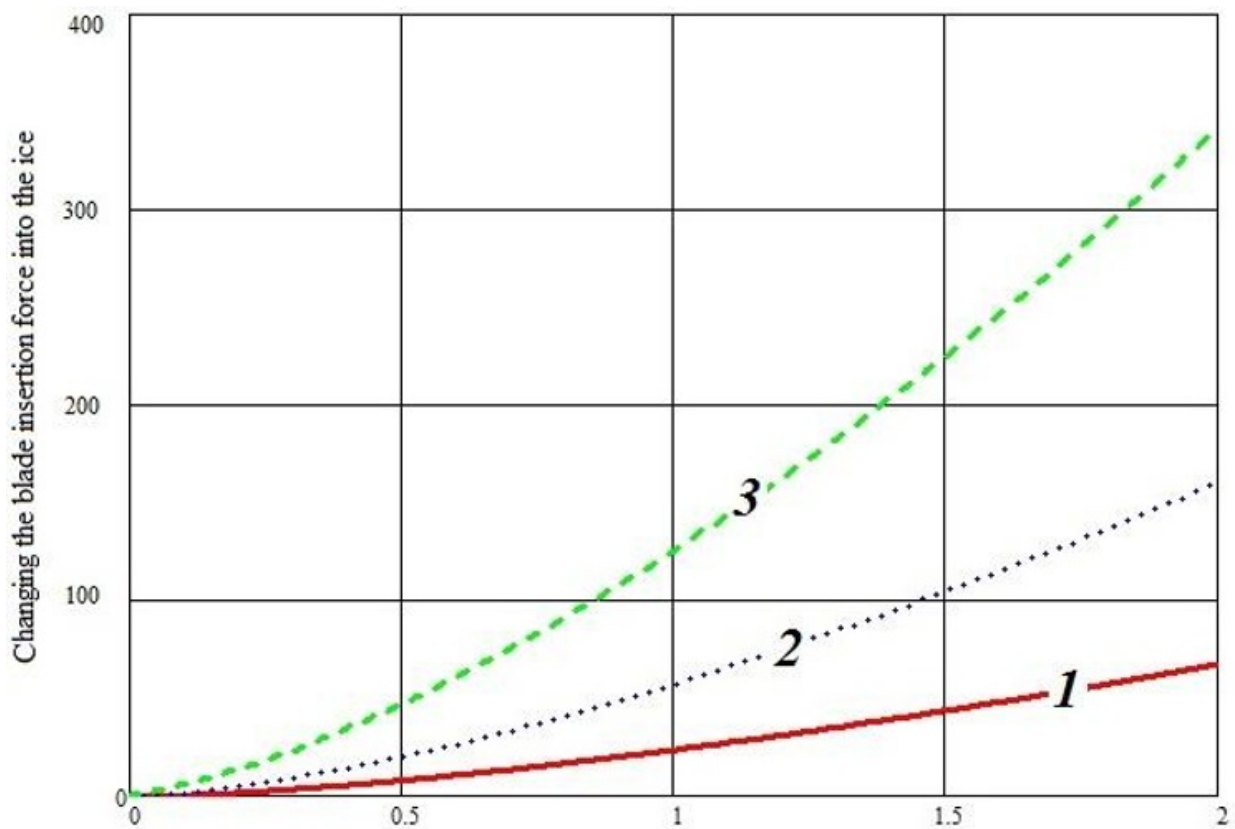

The ratio of height to width of the blade

Fig. 1. The change of the relative cutting force based on the relation of the helical blade height to its width;

1- $\quad$ For the screw blade $0,01 \mathrm{~m}$ wide with the $1 \mathrm{~m}$ base cylinder diameter;

2- $\quad$ For the screw blade $0,01 \mathrm{~m}$ wide with the $1 \mathrm{~m}$ base cylinder diameter;

3 - $\quad$ For the screw blade $0,01 \mathrm{~m}$ wide with the $1 \mathrm{~m}$ base cylinder diameter;

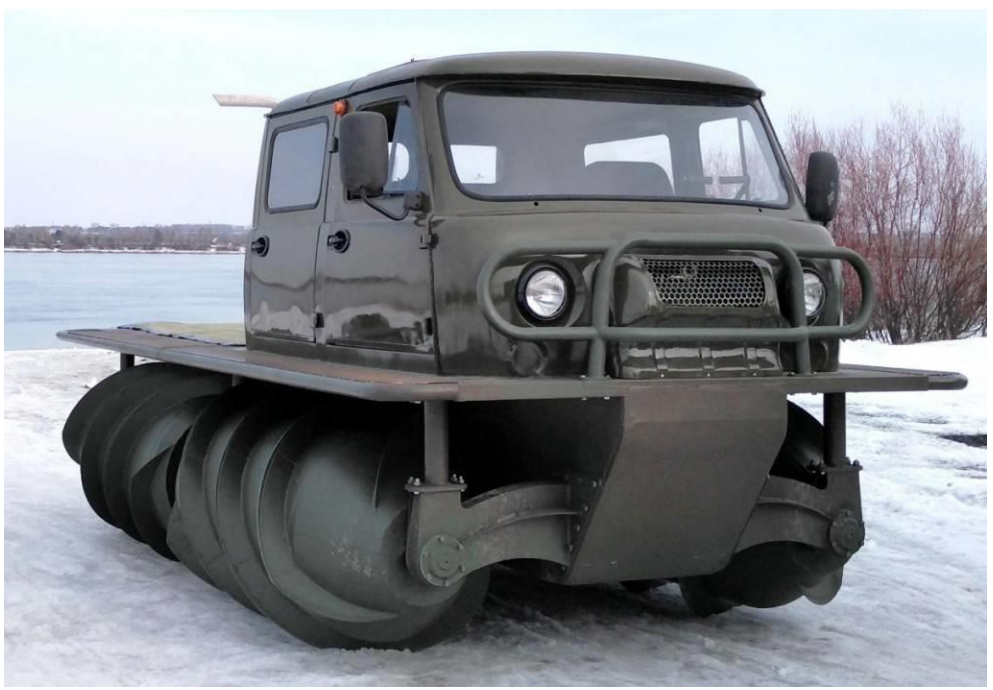

Fig. 2. The prototype of the all-terrain rotary-screw vehicle 


\section{References}

1. M. Krasheninnikov, A. Kulashov, V. Shapkin, A. Koshurina, The concept and methodology of creating the universal life-saver with rotary-screw mover, Lecture Notes in Electrical Engineering, in «Proceedings of the FISITA 2012 World Automotive Congress» 7, 195 (2013)

2. M. Krasheninnikov, A. Koshurina, I. Vasilyev, E. Smirnova, Procedia Engineering 100, 1242-1246 (2015)

3. J.V. Korushova, M.S. Krasheninnikov, A.A. Koshurina, D.A. Lyakhmanov, IOP Conf. Ser.: Mater. Sci. Eng. 393, 012119 (2018)

4. M. Krasheninnikov, A. Kulashov, V. Shapkin, A. Koshurina, The concept and methodology of creating the universal life-saver with rotary-screw mover, Lecture Notes in Electrical Engineering, in «Proceedings of the FISITA 2012 World Automotive Congress» 7, 195 (2013)

5. A.A. Koshurina, M.S. Krasheninnikov, R.A. Dorofeev, Procedia Engineering 150, 1263 1269 (2016)

6. H. Dugoff, I.R. Ehrlich, Model tests of buoyant screw rotor configurations, Journal of Terramechanics 4(3), 9-22 (1967)

7. M. Sturm, J. Holmgren, G.E. Liston, Journal of Climate 8(5),1261-1283 (1995)

8. V.V. Belyakov, A.A. Kurkin, Road bed of transport-technology machines: tutorial (NNSTU, N.Novgorod, 2014)

9. V.V.Belyakov, A.P. Kulyashov, All-terrain transport and technological machines. Fundamentals of the theory of motion (TALAM, N.Novgorod, 2004)

10. V.Y. Kolotilin, A.A. Koshurina, A.P. Kulyashov, L.S. Levshunov, V.A. Shapkin, A.V. Yankovich, Special construction and road machine movers: tutorial (NNSTU, N.Novgorod, 1995)

11. V. Makarov, D. Zeziulin, V. Belyakov, Prediction of all-terrain vehicles mobility in snowscape scenes, in International Conference of the International Society for TerrainVehicle Systems, ISTVS 2014; Convention Center, Hoam Faculty House, Seoul National University, Seoul; South Korea; 22 September 2014 through 25 September 2014; Code 111443 (2014)

12. V. Belyakov, A. Kurkin, V. Makarov, D. Zeziulin, Multifunctional vehicle for coastal areas, in The Twelfth International Conference on the Mediterranear Coastal Environment (MEDCOAST 2015) 06-10 October 2015, Varna, Bulgaria, p. 945-951 ISBN 978-605-85652-3-4 (ISBN 978-605-85652-4-2) (2015)

13. V. Belyakov, A. Kurkin, V. Makarov, D. Zeziulin, D. Minaev, A. Zaytsev, D. Teslenko, Ground vehicle for ice conditions monitoring, in Proceedings of the Thirteenth International MEDCOAST Congress on Coastal and Marine Sciences, Engineering, Management and Conservation, MEDCOAST 2017, 31 October - 4 November 2017, 2017, Mellieha, Malta, E. Ozhan (Editor) p. 775-785 ISBN 978-605-85652-6-5 (ISBN 978-605-85652-8-9) (2017)

14. U.S. Vakhidov, I.A. Yerasov, Y.I. Molev, V.A. Shapkin, Machines for ice, snow and frozen soil development. Monograph (NSTU, N. Novgorod, 2014)

15. A.P. Kulyashov, B.V. Kuznetsov, Y.I. Molev, V.A. Shapkin Ice. Snow. Development techniques (NPK, N. Novgorod, 2002)

16. A.P. Kulyashov, Y.I. Molev, V.A. Shapkin, A.V. Shchepetov Modern methods of ice development (Sputnik+ Publishing House, Moscow, 2005) 
17. V.R. Kargin, B.V. Kargin, Continuum Mechanics. Part 1: Tutorial (SSAU Publishing House, Samara, 2015)

18. Y.A. Vetrov, Cutting ground by earth-moving machines (Mechanical Engineering, Moscow, 1971)

19. V.F. Kulepov Ice breaking machines for technological complexes design and manufacturing. Thesis of the doctor of science, specialty 05.05.04. (N. Novgorod, 2002)

20. A.A. Yeltsov, T.A. Yeltsova, Higher Mathematics II. Integral Calculus. Differential equations: Tutorial (Tomsk State University of Control Systems and Radio-electronics, Tomsk, 2003) 